\title{
Coloured Flashing Lights to Mark Emergency Exits - Experiences from Evacuation Experiments
}

\author{
DANIEL NILSSON ${ }^{1}$, HÅKAN FRANTZICH ${ }^{1}$, and WENDY SAUNDERS ${ }^{2}$ \\ ${ }^{1}$ Department of Fire Safety Engineering, Lund University \\ Lund, Sweden \\ ${ }^{2}$ School of Psychology, Victoria University \\ Melbourne, Australia
}

\begin{abstract}
Three evacuation experiments were performed to investigate how emergency exits should be designed. In the first two experiments coloured flashing lights and strobe lights at emergency exits were tested and compared to a standard emergency exit design. In the third experiment green, blue, orange and red lights were compared to determine which colour was the most appropriate for use in emergencies. Results of the studies show that flashing lights and strobe lights, compared to the standard emergency exit design, increase the use of emergency exits. Furthermore, it is recommended that green lights should be used at emergency exits.
\end{abstract}

KEYWORDS: evacuation experiments, emergency exit, colour, coloured flashing lights, coloured strobe lights

\section{INTRODUCTION}

During an evacuation people will not necessarily use the closest emergency exit, but instead they might use an exit that they are more familiar with. This tendency to move towards familiar exits is often labelled affiliation or movement towards the familiar and was introduced by Sime [1]. The tendency to move towards familiar exits has been observed in many real fires, drills and full-scale evacuation experiments [2,3]. One example is the series of experiments that were performed by Frantzich at three different IKEA stores in Sweden [3]. In this study it was observed that people often walked past emergency exits without using them and many people exited through the main entrance or main exit. This type of behaviour may cause longer evacuation times, which in turn may result in devastating consequences in a real fire. These observations raise an important question: How should emergency exits be designed to encourage more frequent use by evacuees?

In one of the evacuation experiments at the IKEA stores it was observed that two of the emergency exits were used more frequently [3]. The only difference between these two exits and the other emergency exits was their location, relative to the marked walking path in the store. Both of the exits that were used frequently were located along the extension of the walking path, whereas all other exits were located at a ninety degree angle. This result suggests that emergency exits that are located at an angle to the natural walking path of a building might not be used very frequently during evacuation. This problem may be addressed in the design of new buildings, but in some cases, such as tunnels, it might be necessary to place exits at an angle to the direction of the natural walking path. Therefore research should examine how exits can be designed to ensure that they are used during an evacuation.

One example where movement towards familiar exits is potentially dangerous is the case of fires in tunnels. If evacuees choose not to use the emergency exits and instead use the ordinary tunnel exit, they might run out of time and perish in the smoke filled tunnel. 
This scenario has motivated many tunnel designers and researchers to focus on how to design exits in tunnels [4].

The problem concerning movement towards familiar exits has been addressed in a study by Mc Clintock, Shields, Reinhard-Rutland and Leslie [5]. In their study they introduced the theory of learned irrelevance as an explanation for the use of familiar exits. They also tested an alternative design for an emergency exit, which consisted of blue flashing lights that were used in combination with the European standard back-lit emergency exit sign. In the study participants were asked to compare the alternative design with five other designs, using a questionnaire-like survey. The survey revealed that the alternative design had the highest attention capturing ability and was preferred amongst the participants.

In the study by Mc Clintock, Shields, Reinhard-Rutland and Leslie, blue flashing lights were chosen, because it was believed that this colour would be associated with the emergency services in Europe [5]. This association would in turn be beneficial, because there would be a strong link between the emergency exit doors and the emergency services. However, no alternative colours were tested in the study, which gives rise to the following question: Is it possible that flashing lights of a different colour would have preformed even better than the blue flashing lights?

Certain colours are known to have established meanings within populations [6]. An example is the colour green, which often signals go or safety, and the contrasting colour red, which often signals stop or danger. Since it is desirable to attract evacuees to an emergency exit it might be important to use a colour that is associated with safety as well as with emergency exits. Using the correct colour should further improve the effectiveness of flashing lights at emergency exits.

In order to investigate how emergency exits should be designed three experiments were performed at Lund University. The purpose of the study was to examine if coloured flashing lights and strobe lights improved the performance of an emergency exit compared to the standard design. In addition the study aimed to investigate whether green was the most appropriate colour for flashing lights and strobe lights at emergency exits. Finally, the study aimed to explore the associations with different colours in the context of emergencies.

\section{METHOD}

The following section describes three experiments that were performed at Lund University. The first two experiments were performed in August 2003. Based on these experiments one additional experiment was performed in August 2004.

\section{Participants}

The participants were new engineering students at Lund University who intended to study civil engineering, risk engineering, fire safety engineering or surveying. All experiments were performed during orientation day, that is the students' first day at University. This meant that the students had never been inside the building that was used and therefore were unfamiliar with the experiment environment. Each participant only took part once in the experiments, that is only once in one of the three experiments.

The average age of the participants was 22.2 years and ages ranged from 19 to 37 years. Table 1 presents the number of participants and the participants' ages for the different experiments. A total of 172 participants took part in the study. 
Table 1. Age, gender and number of participants in the experiments.

\begin{tabular}{lcccccc}
\hline \multirow{2}{*}{ Experiment } & \multicolumn{3}{c}{ Age } & \multicolumn{3}{c}{ Number of participants } \\
& Mean & Minimum & Maximum & Female & Male & Total \\
\hline 1 & 21.6 & 19 & 37 & 26 & 64 & 90 \\
2 & 22.6 & 19 & 30 & 3 & 29 & 33 \\
3 & 23.1 & 19 & 33 & 14 & 35 & 49 \\
Total & 22.2 & 19 & 37 & 43 & 128 & 172 \\
\hline
\end{tabular}

\section{Experiment 1 - Choice between two Exits in a Corridor}

In the first experiment the participants were faced with a choice between two emergency exits, which were equipped with different way-guidance systems. The experiments were performed in a corridor in the basement of the civil engineering building, Lund University (Fig. 1). The corridor was 37.5 meters long, 3 meters wide and the height from the floor to the ceiling was 3.7 meters. Along one of the walls there were shelves, which reduced the width to 2.6 meters, and at each end of the corridor there was one exit. The lighting consisted of 4 fluorescent light tubes and the luminance at floor level varied between 3 and 72 lux along the centreline of the corridor.

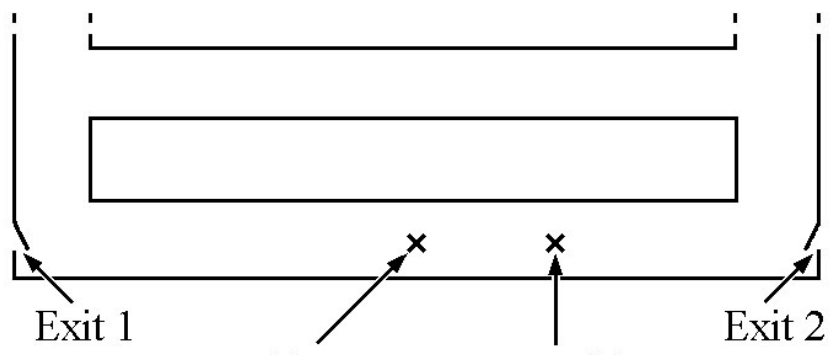

\section{Start position 1 Start position 2}

Fig. 1. The corridor used in the first experiment.

The exit doors were equipped with large windowpanes, which were covered to prevent any daylight from entering the corridor. Both exits were equipped with back-lit emergency exit signs and one of the exits (exit 1 in Fig. 1) was also equipped with additional way-guidance systems, namely different types of flashing lights and strobe lights (Fig. 2). Both orange and green lights were used in the experiments.

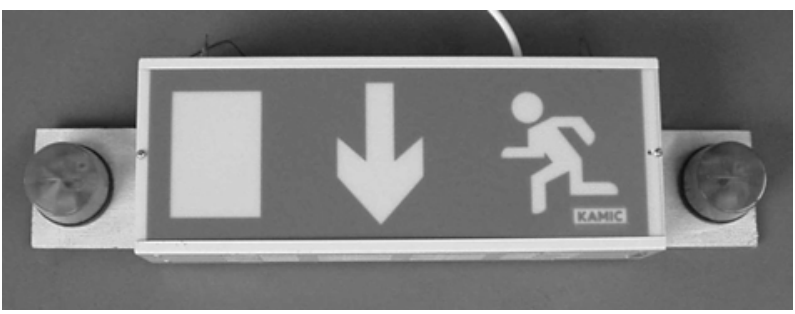

Fig. 2. A back-lit emergency exit sign and green strobe lights.

The start position, that is the location where the participants were placed before the experiment began, was varied. The first start position was located at an equal distance from both exits. For the second start position the distance to exit 1 was twice the distance 
to exit 2. The different combination of way-guidance systems and start positions resulted in six scenarios (Table 2). In one scenario the covering was removed from the windowpanes of the door at exit 2. This was done in order to investigate if daylight influenced the participants' choice of exit.

Table 2. The scenarios for experiment 1.

\begin{tabular}{|c|c|c|c|c|c|}
\hline \multirow{2}{*}{ Scenario } & \multirow{2}{*}{$\begin{array}{l}\text { Start } \\
\text { position }\end{array}$} & \multicolumn{2}{|c|}{ Way-guidance system at exit 1} & \multirow{2}{*}{$\begin{array}{l}\text { Daylight } \\
\text { at exit } 2\end{array}$} & \multirow{2}{*}{$\begin{array}{l}\text { Number of } \\
\text { participants }\end{array}$} \\
\hline & & Flashing lights & Strobe lights & & \\
\hline 1 & 1 & No & No & No & 17 \\
\hline 2 & 1 & Green & No & No & 12 \\
\hline 3 & 1 & No & Green & Yes & 17 \\
\hline 4 & 2 & No & Green & No & 16 \\
\hline 5 & 2 & No & Orange & No & 20 \\
\hline 6 & 2 & Green & No & No & 8 \\
\hline
\end{tabular}

Participants took part in the experiment one at a time and no group interactions were investigated. During the experiments an observer was always present in the corridor. Before the experiment started the participant was blindfolded, led into the corridor by the observer and placed at the appropriate start position facing the wall with exit 1 located on the left and exit 2 on the right. The participant was then told that the observer would be present, but that he or she should not take any notice of the observer and act as if he or she was alone in the corridor. Before the blindfold was removed the participant was given the following instructions:

"Try to imagine the following scenario. You are standing alone in a long corridor and you know that there is a fire in the building, but you do not know where. You want to get out of here, because you want to get to a safe place. Please do so."

When the blindfold was removed the participant was free to choose one of the two exits and their choice was noted by the observer, who remained in the same location throughout the experiment.

All participants completed a questionnaire after the experiment. The questionnaire contained demographic questions as well as questions relating to the experiment and to the participants' associations with different colours in emergencies. In the questionnaire the participants were asked to state what associations they had with the flashing lights or strobe lights that they had just experienced. They could choose between two positive associations, namely safety and come this way, and two negative associations, namely danger and do not come this way, or they could write down associations in their own words.

The questionnaire also contained one part in which the participants were asked about their associations to different colours in emergencies. For each colour they could choose between five alternatives, namely Nothing in particular, Danger, Warning - Keep away, Warning - Look out and Safety. In the questionnaire the colours green, red, orange, yellow and white where evaluated. A small box that was filled with colour was placed adjacent to each question (Fig. 3). 


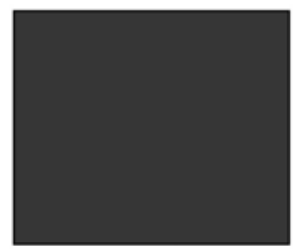

15. Röd

O Inget speciellt

O Fara

O Varning - håll dig borta

O Varning - se upp

O Säkerhet

Fig. 3. A question relating to the participants’ associations with the colour red.

The part of the questionnaire that dealt with the associations with different colours was also given to 61 third year students at Lund University who did not take part in the experiments. One question relating to the associations with blue was added to the questionnaire that was completed by the 61 students.

\section{Experiment 2 - Choice of an Alternative Exit in a Corridor}

The second experiment was performed in the same corridor as the first experiment, but the start position as well as the location of emergency exits signs and way-guidance systems were altered (Fig. 4). The emergency exit at the other end of the corridor was clearly visible from the start position and the windowpanes of the door were not covered. As the participants moved through the corridor an alternative emergency exit became visible to them on the left hand side. Both the exit at the end of the corridor and the alternative emergency exit were equipped with back-lit emergency exit signs. In addition green strobe lights were mounted at the alternative emergency exit.

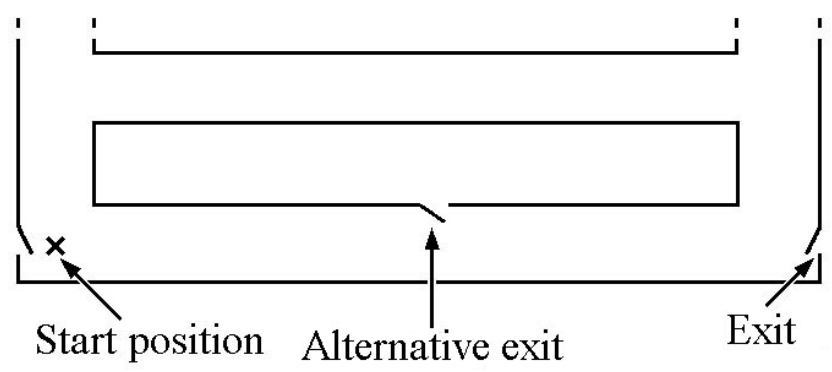

Fig. 4. The corridor used in the second experiment.

Two different scenarios were used in the second experiment (Table 3). Only one start position was used, and the strobe lights were only turned on in the second scenario.

Table 3. The scenarios for experiment 2.

\begin{tabular}{ccc}
\hline Scenario & Strobe lights at alternative exit & Number of participants \\
\hline 1 & No & 16 \\
2 & Green & 17 \\
\hline & & $\Sigma: 33$
\end{tabular}

The procedure was very similar to that of Experiment 1. Participants took part in the experiment one at a time and an observer was always present in the corridor. Before the experiment started the participant was blindfolded, led into the corridor by the observer and placed at start position facing the exit at the other end of the corridor. The participant 
was then told that the observer would be present, but that he or she should not take any notice of the observer and act as if he or she was alone in the corridor. Before the blindfold was removed the participant was given the following instructions:

"Try to imagine the following scenario. You are standing alone in a long corridor and you know that there is a fire somewhere behind you. You want to get out of here, because you want to get to a safe place. Please do so."

When the blindfold was removed the participant was free to walk towards the exit at the end of the corridor. When they had walked approximately 12 meters they could see the alternative exit on the left hand side. Their choice of exit was noted by the observer, who walked a few meters behind the participant in the experiment.

After the experiment the participants completed a questionnaire that contained questions relating to the experiment as well as their associations with different colours in emergencies. The questions relating to the associations with colours were identical to the questions used in the first experiment.

\section{Experiment 3 - A Comparison between Different Flashing Lights and Strobe Lights}

In the third experiment the participants sat down in front of a display of flashing coloured lights and strobe lights. Four different colours were used, namely green, blue, red and orange. The display also included one back-lit and a front illuminated emergency exit sign.

Participants were told to imagine that the flashing lights or strobe lights were going to be used in combination with an emergency exit sign. They were then asked to grade the extent to which they associated the different lights with an emergency exit. The degree of association was graded according to a seven point scale from do not at all associate with an emergency exit (1) to associate very much with an emergency exit (7).

\section{RESULTS}

In the following section the results of the three experiments are presented. In the analysis of the results a significance level of .05 was used for all statistical tests.

\section{Experiment 1 - Choice between two Exits in a Corridor}

The participants' choice of exit in Experiment 1 is presented in Table 4. Two participants are not included in the table because they did not choose an exit, but instead they stood still and waited for further instructions.

Table 4 shows that equal proportions of the participants used exits 1 and 2 in the scenario where no way-guidance system was used. It can also be seen that the participants had a tendency to walk towards exit 1 regardless of which way-guidance system was used at that exit. Of the 72 people who were exposed to flashing or strobe lights only 22, that is 31 percent, chose to walk to exit 2 that was only equipped with a back-lit emergency exit sign. A sign test was performed to determine if the result, that is the participants' choice of exit, was significant. The test revealed that the participants were significantly more likely to walk towards the exit that was equipped with flashing lights or strobe lights, $p=.001$. 
Table 4. The participants' choice of exit in the first experiment.

\begin{tabular}{|c|c|c|c|c|c|c|}
\hline \multirow{2}{*}{ Scenario } & \multirow{2}{*}{$\begin{array}{c}\text { Start } \\
\text { position }\end{array}$} & \multicolumn{2}{|c|}{$\begin{array}{l}\text { Way-guidance } \\
\text { system at exit } 1\end{array}$} & \multirow{2}{*}{$\begin{array}{l}\text { Daylight } \\
\text { at exit } 2\end{array}$} & \multicolumn{2}{|c|}{$\begin{array}{l}\text { Number (proportion) of } \\
\text { participants who walked to }\end{array}$} \\
\hline & & $\begin{array}{c}\text { Flashing } \\
\text { lights }\end{array}$ & $\begin{array}{l}\text { Strobe } \\
\text { lights }\end{array}$ & & Exit 1 & Exit 2 \\
\hline 1 & 1 & No & No & No & 8 (50 \%) & 8 (50 \%) \\
\hline 2 & 1 & Green & No & No & 9 (75 \%) & 3 (25 \%) \\
\hline 3 & 1 & No & Green & Yes & 11 (65 \%) & $6(35 \%)$ \\
\hline 4 & 2 & No & Green & No & 12 (75 \%) & $4(25 \%)$ \\
\hline 5 & 2 & No & Orange & No & 11 (58 \%) & $8(42 \%)$ \\
\hline 6 & 2 & Green & No & No & 7 (88\%) & 1 (12 \%) \\
\hline
\end{tabular}

In the questionnaire the participants were asked to state their associations with the flashing lights or strobe lights that they had just experienced. The different alternatives were classified as either positive or negative, and some participants also wrote their associations using their own words. All the associations that the people expressed in their own words were neither clearly positive nor negative and they were thus classified as neutral.

Table 5 shows the participants' associations with the flashing lights or strobe lights and only those participants who saw the lights are included. It can be seen in the table that they associated the green flashing light with positive alternatives to a greater extent than the green strobe light, which in turn was associated to a greater extent with positive alternatives than the orange strobe light. The reverse trend is also true for the negative associations.

Table 5. The participants' associations with different types of lights.

\begin{tabular}{lcccc}
\hline \multirow{2}{*}{ Type of light } & \multicolumn{2}{c}{ Number (proportion) of participants } & Total number \\
\cline { 2 - 4 } & $\begin{array}{c}\text { Positive } \\
\text { association }\end{array}$ & $\begin{array}{c}\text { Neutral } \\
\text { associations }\end{array}$ & $\begin{array}{c}\text { Negative } \\
\text { associations }\end{array}$ & of participants \\
\hline Green flashing light & $13(72 \%)$ & $0(0 \%)$ & $4(22 \%)$ & 18 \\
Green strobe light & $17(59 \%)$ & $2(7 \%)$ & $9(31 \%)$ & 29 \\
Orange strobe light & $5(36 \%)$ & $2(14 \%)$ & $7(50 \%)$ & 14 \\
\hline
\end{tabular}

In the questionnaires used in Experiments 1 and 2 the participants were asked about their associations with different colours in emergencies. These associations are presented in Table 6 . In the table it can be seen that green was mainly associated with safety whereas red was mainly associated with danger. It is also worth noting that yellow, blue and white were generally not associated with anything in particular however yellow along with orange was associated with warning. 
Table 6. The participants' associations with different colours. The association stated by more than 25 percent of the participant are underlined $(=$ ).

\begin{tabular}{lcccccc}
\hline Colour & Danger & $\begin{array}{c}\text { Warning - } \\
\text { Keep away }\end{array}$ & $\begin{array}{c}\text { Warning - } \\
\text { Look out }\end{array}$ & Safety & $\begin{array}{c}\text { Nothing in } \\
\text { particular }\end{array}$ & $\begin{array}{c}\text { Number of } \\
\text { participants }\end{array}$ \\
\hline Green & $0 \%$ & $0 \%$ & $0 \%$ & $\underline{82,6 \%}$ & $16,8 \%$ & 184 \\
Red & $\underline{65,2 \%}$ & $17,9 \%$ & $12,0 \%$ & $2,2 \%$ & $2,7 \%$ & 184 \\
Orange & $14,1 \%$ & $24,5 \%$ & $\underline{\underline{41,8 \%}}$ & $2,2 \%$ & $16,8 \%$ & 184 \\
Yellow & $3,3 \%$ & $4,9 \%$ & $\underline{\underline{29,9 \%}}$ & $1,6 \%$ & $\underline{\underline{59,8 \%}}$ & 184 \\
White & $0 \%$ & $0,5 \%$ & $0,5 \%$ & $14,7 \%$ & $\underline{\underline{83,2 \%}}$ & 184 \\
Blue & $1,6 \%$ & $0 \%$ & $1,6 \%$ & $14,8 \%$ & $\underline{\underline{77,0 \%}}$ & 61 \\
\hline
\end{tabular}

\section{Experiment 2 - Choice of an Alternative Exit in a Corridor}

Eight out of the 33 participants who took part in the second experiment did not react after they had received the instructions and required prompting again before they started to move towards the exit. These eight participants were therefore excluded in the analysis of the results. The exit choice of the remaining 25 participants is displayed in Table 7. It can be seen that a greater proportion of the participants who were exposed to the green strobe lights used the alternative exit.

Table 7. The participants' choice of exit in the second experiment.

\begin{tabular}{|c|c|c|c|}
\hline \multirow{2}{*}{ Scenario } & \multirow{2}{*}{$\begin{array}{l}\text { Strobe lights at } \\
\text { alternative exit }\end{array}$} & \multicolumn{2}{|c|}{ Number (proportion) of participants who walked to } \\
\hline & & Alternative exit & Exit at the end of the corridor \\
\hline 1 & No & $6(55 \%)$ & $5(45 \%)$ \\
\hline 2 & Green & $13(93 \%)$ & $1(7 \%)$ \\
\hline
\end{tabular}

\section{Experiment 3 - A Comparison between Different Flashing Lights and Strobe Lights}

The participants in the third experiment graded their associations with an emergency exit for four strobe lights and four flashing lights. The scale used consisted of 7 steps, where 1 was the lowest level of association and 7 was the highest. Based on the participants' ratings, calculations were performed to identify when the green flashing light was associated more, equal or less with an emergency exit, than the red, orange and blue flashing lights (Table 8). The same calculations were performed for the strobe lights (Table 9). It can be seen in Table 8 and 9 that more participants rated green higher than red, orange and blue, for both the flashing lights and strobe lights.

Table 8. The number of participants who associated the green light more, equal or less with an emergency exit for the flashing lights.

\begin{tabular}{lcccc}
\hline \multirow{2}{*}{ Other light } & \multicolumn{3}{c}{ Number of participants } & Results from the sign test \\
\cline { 2 - 4 } & $\begin{array}{c}\text { Green } \\
\text { more }\end{array}$ & $\begin{array}{c}\text { No } \\
\text { difference }\end{array}$ & $\begin{array}{c}\text { Green } \\
\text { less }\end{array}$ & $P$ \\
\hline Red & 25 & 9 & 13 & .073 \\
Orange & 27 & 7 & 14 & .060 \\
Blue & 29 & 13 & 7 & $<.001$ \\
\hline
\end{tabular}


Table 9. The number of participants who associated the green light more, equal or less with an emergency exit for the strobe lights.

\begin{tabular}{lcccc}
\hline \multirow{2}{*}{ Other light } & \multicolumn{3}{c}{ Number of participants } & Results from the sign test \\
\cline { 2 - 4 } & $\begin{array}{c}\text { Green } \\
\text { more }\end{array}$ & $\begin{array}{c}\text { No } \\
\text { difference }\end{array}$ & $\begin{array}{c}\text { Green } \\
\text { less }\end{array}$ & $P$ \\
\hline Red & 27 & 8 & 12 & .024 \\
Orange & 25 & 6 & 16 & .211 \\
Blue & 30 & 13 & 5 & $<.001$ \\
\hline
\end{tabular}

Six sign tests were performed to determine whether the green flashing lights and green strobe lights were generally associated more with an emergency exit than the other type of lights. The results of the significance tests are reported in Table 8 and 9. It can be seen in the tables that both the green flashing light and the green strobe light were significantly more often associated with an emergency exit than the blue lights. The result for the red strobe light was also significant, but all other results in Table 8 and 9 were not significant. (The authors recognize that multiple significance tests using the same data may increase the risk of rejecting null hypotheses although they might be true. This problem can partially be addressed by reducing the significance level.) No significant differences were found between the participants' associations with flashing lights versus strobe lights.

\section{DISCUSSION AND CONCLUSIONS}

The results of the study show that emergency exits that are equipped with flashing lights or strobe lights are chosen more frequently than ordinary emergency exits, that is exits that are only equipped with an emergency exit sign. This suggests that flashing lights or strobe lights will increase the use of an emergency exit compared to the standard design, and thereby make emergency exits better. The effectiveness of the combination of emergency exit signs and flashing lights has also been demonstrated by Mc Clintock, Shields, Reinhard-Rutland and Leslie in a previous study [5].

The purpose of the second experiment was to investigate if green strobe lights could influence the use of an alternative exit during evacuation. In the experiment a greater proportion of the participants used the alternative exit when strobe lights were used. This result implies that flashing lights and strobe lights may be an effective way of making people notice and choose alternative exits that become visible to them as they move through the building. By actively making people aware of alternative exits it may be possible to break the tendency of movement towards familiar exits.

It is believed that the main benefit of the flashing lights and strobe lights is that they direct the evacuees' attention to and make them notice emergency exit signs, which in turn convey the information about the presence of an exit. This belief has also been presented previously by Frantzich and Nilsson in a study on evacuation from smoke filled tunnels [4]. In that study it was found that only those people who saw flashing lights in combination with an emergency exit sign walked out through an exit, whereas those who only saw the flashing lights did not. Although it is believed that the information about the existence of an exit is mainly conveyed through the sign, it is postulated that the colour of the flashing lights influences how well the way-guidance system works. Certain colours are known to have well established meaning [6]. Green often implies safety or go and may therefore be more appropriate to use than for example red, which often signals danger or stop. It is probable that green flashing lights will encourage people to look 
towards the sign and use the exit, whereas red might be discouraging. In the present study it was confirmed that green was associated with safety and that red was associated with danger, in emergencies. It was also apparent that yellow, white and blue were associated with nothing in particular and that yellow and orange were associated with different degrees of warning.

In the study by Mc Clintock, Shields, Reinhard-Rutland and Leslie blue flashing lights were used and it was hypothesised that this colour would be associated with the emergency services [5]. This association would in turn be beneficial, because there would be a strong link between the emergency exit doors and the emergency services. However, in the third experiment of the present study the blue flashing lights and strobe lights were rated significantly lower than the equivalent green lights, which implies that people are more likely to associate green lights with an emergency exit. The same trend was observed for red and orange lights, but these results were not significant. Furthermore, the colour blue was generally associated with nothing in particular in the context of emergencies, although it should be noted that the association with the emergency services was not one of the alternatives provided to respondents. Given these results, it is possible that the explanation provided in previous studies, for the success of the flashing blue lights, in terms of a link between the emergency services and emergency exit, may not be completely correct. Instead, it is possible that the blue flashing lights performed well mainly because they were the only flashing lights tested in the study.

In the first experiment the participants were asked to state their associations with the flashing lights and strobe lights to which they had been exposed. The results show that the participants' associations with the green lights were positive and their associations with the orange lights were negative. Also, it can be seen in the results of scenario 4, 5 and 6 that a higher proportion of the participants walked to exit 1, that is the exit equipped with the additional way-guidance system, for the green flashing lights. The only difference between these three scenarios is the colour of the lights that were used at exit 1.

The results of the study show that flashing lights and strobe lights increase the use of an emergency exit compared to the standard emergency exit design. This conclusion has implications for the design of exits in buildings and it is recommended that all emergency exits should be equipped with green flashing lights. Green is believed to be the most appropriate colour, because it is interpreted as safety and go. As has been pointed out in previous research [5] the flashing lights must only activate when the building is going to be evacuated thus making it suitable to connect the system to the evacuation alarm. By installing flashing lights at all the emergency exits it may be possible to direct people to the desired exits and hence break the trend of movement towards familiar exits. Future research should focus on testing way-guidance systems in real buildings to investigate to what extent flashing green lights can influence peoples' choice of exit during evacuation.

\section{REFERENCES}

[1] Sime, J.D., "Movement Towards the Familiar - Person and Place Affiliation in a Fire Entrapment Setting,” Environment and Behaviour, 17 (6), 1985, pp. 697724.

[2] Shields, T.J. and Boyce, K.E., "A Study of Evacuation from Large Retail Stores,” Fire Safety Journal, 35, 2000, pp. 25-49. 
[3] Frantzich, H., "Occupant Behaviour and Response Time - Results from Evacuation Experiments," Human Behaviour in Fire - Proceedings of the Second International Symposium, Boston, USA, 2001, pp. 159-165.

[4] Frantzich, H. and Nilsson, D., "Evacuation Experiments in a Smoke Filled Tunnel," Human Behaviour in Fire - Proceedings of the Third International Symposium, Belfast, UK, 2004, pp. 229-238.

[5] Mc Clintock, T., Shields, T.J., Reinhardt- Rutland, A.H. and Leslie, J.C., "A Behavioural Solution to the Learned Irrelevance of Emergency Exit Signage," Human Behaviour in Fire - Proceedings of the Second International Symposium, Boston, USA, 2001, pp. 23-33.

[6] Wickens, C.D. and Hollands, J.G., Engineering Psychology and Human Performance, Prentice Hall, New Jersey, 2000. 
